\title{
Comparison of Ribbond and Everstick Post in Reinforcing the Re-attached Maxillary Incisors Having Two Oblique Fracture Patterns: An In Vitro Study
}

\author{
Deeksha Khurana $^{1}$, Ashwini B Prasad ${ }^{2}$, Deepak Raisingani ${ }^{3}$, Harshit Srivastava ${ }^{4}$, Prachi Mital ${ }^{5}$, Namita Somani ${ }^{6}$
}

\begin{abstract}
Aim and objective: This study aims to compare the resistance to fracture in maxillary incisors which were fractured in two different oblique patterns and then were re-attached and reinforced using anatomic fiber-reinforced composite (FRC) post.

Materials and methods: Sixty extracted and intact human maxillary incisors were obtained and divided into two groups (A and B; $n=30$ ). "Labiopalatal" and "palatolabial" fractures were induced in group A and group B, respectively. These two groups were further subdivided into two subgroups $(n=15)$. In subgroup I Ribbond fiber (Ribbond Inc., Seattle, WA, USA) and in subgroup II Everstick post (everStick Post ${ }^{\mathrm{TM}}$, GC Corporation, Tokyo, Japan) were used. Fractured fragments were re-attached using resin and tested for fracture resistance in universal testing machine. Statistical analysis was done with ANOVA one-way test and post hoc test.

Results: The labiopalatal fracture pattern of group A showed significantly increased resistance to fracture than the palatolabial fracture pattern of group B in both the subgroups. Similarly, subgroup II with Everstick post exhibited significantly higher fracture resistance than subgroup I with Ribbond in both groups A and B ( $p$ value $<0.05$ ).

Clinical significance: The study simulates a clinical scenario of coronal fracture of a tooth and focuses on the techniques and materials which can be used for successful management of such cases.

Keywords: Everstick post, Fracture resistance, Re-attachment, Ribbond.

International Journal of Clinical Pediatric Dentistry (2021): 10.5005/jp-journals-10005-2035
\end{abstract}

\section{INTRODUCTION}

Fracture of the anterior teeth is common among all dental traumatic injuries and is usually seen among school children between 6 years and 18 years of age. In around $30 \%$ of children, traumatic dental injuries are seen in primary dentition while $22 \%$ of children report trauma to the permanent dentition. ${ }^{1}$ The teeth most vulnerable to trauma are maxillary incisors due to their position in the arch and their eruptive pattern. ${ }^{2}$ Pagliarini et al. stated that fractures of crowns of permanent incisors constitutes $18-22 \%$ of all dental traumas with $96 \%$ of cases occurring in maxillary incisors. ${ }^{3}$

Management of these coronal fractures, especially complicated ones, often presents restorative challenges. Root canal treatment followed by re-attachment of the fractured segment, when available, is a feasible option in managing such cases. ${ }^{4}$

Re-attachment of the fractured segment was first introduced by Chosack and Eidelman ${ }^{5}$ in 1964 . It allows rehabilitation of function and esthetics almost immediately and thus creates a positive psychological response; ${ }^{6}$ however, factors like direction and extension of fracture lines, fit and pattern of the fractured fragments have to be considered for determining the sustainability of re-attached fractured fragments. ${ }^{7,8}$

Re-attached fractured segments can be reinforced using fiber posts, which are available as customized or prefabricated post systems. Customized fiber-reinforced composite (FRC) posts are preferred over the prefabricated ones as they fit the size of the canal lumen thus minimizing the weak interface of cement. ${ }^{8,9}$

In the present in vitro study, two customized FRC post systems, Ribbond fiber (Ribbond Inc., Seattle, WA, USA) and Everstick (everStick Post ${ }^{\mathrm{TM}}$, GC Corporation, Tokyo, Japan), were used.
${ }^{1-5}$ Department of Conservative Dentistry and Endodontics, Mahatma
Gandhi Dental College and Hospital, Jaipur, Rajasthan, India
${ }^{6}$ Department of Conservative Dentistry and Endodontics, Darshan
Dental College and Hospital, Jaipur, Rajasthan, India

Corresponding Author: Deeksha Khurana, Department of Conservative Dentistry and Endodontics, Mahatma Gandhi Dental College and Hospital, Jaipur, Rajasthan, India, Phone: +91 7023609297, e-mail: khurana.deeksha297@gmail.com

How to cite this article: Khurana $D$, Prasad $A B$, Raisingani $D$, et al. Comparison of Ribbond and Everstick Post in Reinforcing the Reattached Maxillary Incisors Having Two Oblique Fracture Patterns: An In Vitro Study. Int J Clin Pediatr Dent 2021;14(5):689-692.

Source of support: Nil

Conflict of interest: None

Ribbond has a three-dimensional leno-weaved triaxial braided structure, which renders mechanical interlocking of composite resin in various planes. $8,10-12$

Everstick is a soft, pliable individually formable glass fiber post impregnated with resin. ${ }^{13,14}$

This research was undertaken as literature has limited data describing these two oblique fracture patterns and their re-attachment and reinforcement technique.

\section{Materials and Methods}

Sixty extracted intact human maxillary incisors with fully formed apex were collected and divided into two groups (group $A$ and group B) each having 30 samples. In group A-“Labiopalatal” 
fracture was induced, i.e., crowns of teeth were fractured in a way so that the remaining crown structure on the labial side is $6 \mathrm{~mm}$ and on the palatal side is $2 \mathrm{~mm}$. In group B-"Palatolabial" fracture was induced, i.e., crowns of teeth were fractured in a way so that the remaining crown structure on the labial side is $2 \mathrm{~mm}$ and on the palatal side is $6 \mathrm{~mm}$ (Fig. 1). Safe-ended diamond disc was used to induce the fracture and measurements were done using a digital Vernier caliper.

For standardization, the middle point of the cementoenamel junction (CEJ) was used for reference. The sectioned fragments were kept in distilled water until they were re-attached.

In all the specimens, biomechanical preparation was done up to size $60 \mathrm{~K}$ hand files (Dentsply Maillefer, Ballaigues, Switzerland). Irrigation was done using 17\% EDTA, 5.25\% concentration of $\mathrm{NaOCl}$ and, final irrigation with saline. Canals were dried using paper points and the apical region of $5 \mathrm{~mm}$ was sectionally obturated using $\mathrm{AH}$ plus sealer (AH Plus Dentsply DeTrey GmbH, Konstanz, Germany). Post space preparation was done with Peeso Reamers up to size 4.

\section{Subgrouping}

Samples of group A and group B were divided into two subgroups I (Ribbond) and II (Everstick post) according to the post used for reinforcing the re-attachment. Each subgroup consisted of 15 samples.

\section{Post Placement and Fragment Re-attachment}

Subgroup I: Ribbond (15 Samples Each in Groups A and B)

Fifteen samples each in group $A$ and group $B$ were reinforced with Ribbond fiber (Ribbond Inc., Seattle, WA, USA, $3 \mathrm{~mm}$ ). Canal walls were etched, bond, and cured. Ribbond fiber of a length twice the length of the post space was cut, wetted in resin, and placed and pushed into the post space. If space permitted, an additional piece of Ribbond was also placed. It was cemented using the solocem self-etch self-adhesive resin cement (Coltene Whaledent, USA). After cementation of the post, the fit of the fractured segments was checked, followed by etching, priming, and re-attachment with a flowable composite $\left(3 \mathrm{M}^{\mathrm{TM}}\right.$ ESPE $^{\mathrm{TM}}$ Filtek $^{\mathrm{TM}}$ Supreme XTE, USA) using curing light for 40 seconds. Protruding free ends of the Ribbond aided in reinforcing the re-attachment of the fragment. To merge the fragments, chamfer margin was given on the fracture line which was restored with flowable composite.

\section{Subgroup II: Everstick Post (15 Samples Each in Groups A and B)}

Fifteen samples each in group $A$ and group $B$ were reinforced using Everstick posts (everStick Post ${ }^{\mathrm{TM}}$, GC Corporation, Tokyo, Japan- size $1.2 \mathrm{~mm}$ ). Everstick fiber was cut to the desired length. The post was

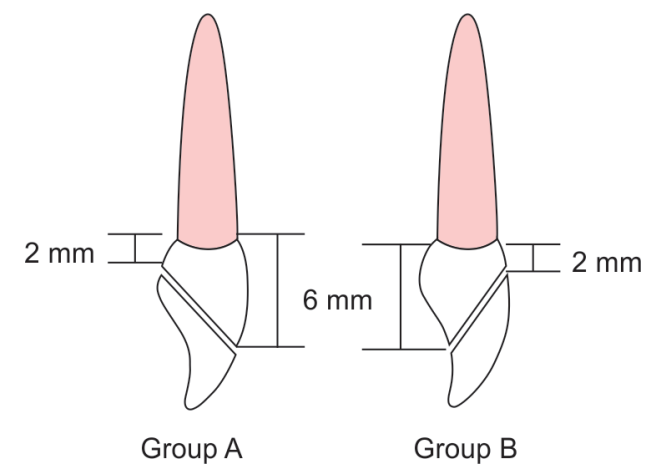

Fig. 1: Group A: Labiopalatal fracture pattern; Group B: Palatolabial fracture pattern cemented in the canal in a similar method as described for subgroup I using solocem resin cement. The post fiber and cement were lightcured for at least 40 seconds. Re-attachment of the fragments was done similarly as described above.

Roots of all the samples were coated with a thin polyvinyl siloxane impression material layer to simulate periodontal ligament and then embedded in preformed resin mold till $2 \mathrm{~mm}$ below the CEJ.

\section{Testing the Fracture Resistance}

Constant loading of the samples was done in a universal testing machine (Instron) at a crosshead speed of $1 \mathrm{~mm} \mathrm{~min}^{-1}$ until they fractured. The acrylic block holding the tooth was positioned in a way to provide $4^{\circ}$ angle between the loading tip and the palatal surface with a loading tip contacting the samples $2 \mathrm{~mm}$ below incisal edges. Unit of load was recorded in Newtons.

\section{Statistical Data Analysis}

ANOVA one-way test was used for comparing the mean resistance values and a post hoc test was used for multiple comparisons using SPSS 23.0. " $p$ " value $<0.05$ indicated a significant difference.

\section{Results}

Teeth samples in group A having labiopalatal fracture patterns exhibited significantly increased fracture resistance compared to the samples in group $B$ having palatolabial fracture patterns for all the specimens $(p<0.05)$ (Table 1$)$.

Within group $A$, the teeth restored with Everstick post (subgroup II) showed greater fracture resistance (725.5 $\pm 59.6 \mathrm{~N}$ ) than Ribbond (subgroup I) $(517.4 \pm 72.0$ N) (Table 2).

Similarly, within group $B$, the teeth restored with Everstick post (subgroup II) exhibited higher fracture resistance $(617.0 \pm 81.8 \mathrm{~N})$ than Ribbond (subgroup I) $(423.2 \pm 80.5 \mathrm{~N}$ ) (Table 2).

\section{Discussion}

Reconstruction strategies for coronal fractures have evolved through the years and several techniques for their management have been developed. The present in vitro study represents a clinical scenario of a complicated crown fracture with available intact fractured fragments and gives an insight into techniques and restorative materials which can prove helpful in the management of such cases.

In cases of complicated crown fractures and where the fractured fragment is available, re-attachment of the fragment to the tooth with the help of a root canal post is considered as the choice of treatment. It is suggested that the pulp chamber space aids in the inner reinforcement, thus further preparation of the fractured tooth is not required., 7,15

Literature reports that $85 \%$ of traumatized incisors fracture in an oblique direction. ${ }^{16,17}$ Thus, two oblique patterns of fractures (labiopalatal and palatolabial) in maxillary incisors have been evaluated for fracture resistance in the present study and they were standardized as per the in vitro study by Ramesh et al. ${ }^{8}$

To induce fracture and obtain coronal fragments, sectioning was done with a diamond disc as it helped in achieving a uniform fracture line involving the pulp chamber, along with providing a smooth surface with minimal defects at the interface. ${ }^{18,19}$ To prevent desiccation and retain the original color of the fractured fragments obtained after sectioning they were kept in distilled water until 
Comparison of Ribbond and Everstick Post for Reinforcement of Re-attached Maxillary Incisors with Two Fracture Patterns

Table 1: Comparison of fracture resistance (Newtons) of teeth having the two fracture patterns restored with Ribbond and Everstick post

\begin{tabular}{lllllll}
\hline & Group & $N$ & Mean & SD & Median & pvalue \\
\hline $\begin{array}{l}\text { Subgroup I } \\
\text { (Ribbond) }\end{array}$ & $\begin{array}{l}\text { Group A (Labio- } \\
\text { palatal) }\end{array}$ & 15 & 517.4 & 72.0 & 513.00 & 0.00218 \\
& $\begin{array}{l}\text { Group B (Palato- } \\
\text { labial) }\end{array}$ & 15 & 423.2 & 80.5 & 419.00 \\
$\begin{array}{l}\text { Subgroup II } \\
\text { (Everstick Post) }\end{array}$ & $\begin{array}{l}\text { Group A (Labio- } \\
\text { palatal) } \\
\text { Group B (Palato- }\end{array}$ & 15 & 725.5 & 59.6 & 735.00 & 0.00032 \\
& 15 & 617.0 & 81.8 & 632.00 \\
\hline
\end{tabular}

Table 2: Comparison of fracture resistance (Newtons) of teeth restored with Ribbond and Everstick post with two different fracture patterns

\begin{tabular}{lllllll}
\hline Groups & Subgroups & $N$ & Mean & SD & Median & 0.000 \\
\hline $\begin{array}{l}\text { Group A (Labio- } \\
\text { palatal) }\end{array}$ & $\begin{array}{l}\text { Subgroup I } \\
\text { (Ribbond) }\end{array}$ & 15 & 517.4 & 72.0 & 513 & 735 \\
& $\begin{array}{l}\text { Subgroup II } \\
\text { (Everstick Post) }\end{array}$ & 15 & 725.5 & 59.6 & 419.000 & 0.000 \\
$\begin{array}{l}\text { Group B (Palato- } \\
\text { labial) }\end{array}$ & $\begin{array}{l}\text { Subgroup I } \\
\text { (Ribbond) }\end{array}$ & 15 & 423.2 & 80.5 & 632.00 \\
& $\begin{array}{l}\text { Subgroup II } \\
\text { (Everstick Post) }\end{array}$ & 15 & 617.0 & 81.8 & & \\
\hline
\end{tabular}

their re-attachment. This has also been shown to increase the bond strengths. ${ }^{20}$

Researchers have evaluated various types of posts materials like cast, glass, polyethylene woven, carbon, quartz fiber, and have advocated that FRC posts are a promising alternative to rigid old traditional root canal post materials. It can be attributed to the fact that they have a modulus of elasticity similar to the dentin, thus reducing the risk of fracture of the roots. $9,10,21,22$

Thus, in the present in vitro study, two different FRC posts (Ribbond and Everstick) were evaluated and compared.

Ribbond is a customized woven polyethylene fiber post consisting of a spectrum of bondable, reinforced polyethylene fibers with ultra-high-strength. It has a high coefficient of elasticity (117 GPa) making it highly stretch, distortion, and traction (3 GPa) resistant. ${ }^{11,23}$ Everstick post has interpenetrating polymer network (IPN) and elasticity modulus alike that of dentin (15-20 GPa), facilitating even distribution of occlusal stresses. ${ }^{13}$

For re-attachment of fractured fragments, circumferential chamfer was made on the line of fracture as Yilmaz et al. ${ }^{19}$ have advocated that it increases the retention of the fragments by ensuring a precise fit.

Fracture resistance was tested using a universal Instron testing machine under constant load applied at a constant speed of $1 \mathrm{~mm}$ per minute until fracture occurred. This standardized speed was used as per the studies by Ramesh et al., ${ }^{8}$ Newman et al., ${ }^{24}$ and Dean et al. ${ }^{25}$

In this in vitro investigation, it was found that on the application of palatal load, the sample teeth having labiopalatal fracture pattern (group $A$ ) showed significantly increased fracture resistance than the palatolabial group (group B), $p<0.05$. In an in vitro study by Ramesh et al., ${ }^{8}$ a similar result was obtained and this can be attributed to the fact that the remaining labial tooth structure provided the support to the fragment, thus contributing to the increased fracture resistance.

Everstick post is a glass FRC post and performed significantly better than Ribbond which is a polyethylene fiber. Mangoush et al. ${ }^{26}$ observed a similar finding that glass FRCs have superior characteristics and provide significantly better reinforcement than polyethylene FRCs. This is due to the difficulty in silanization and impregnation of polyethylene fibers leading to weak adhesion of the resin to polyethylene FRC whereas, in glass FRC materials, adhesion is promoted by silane coupling agents.

Everstick post showed high fracture resistance for both the fracture patterns (725.5 and $617.0 \mathrm{~N}$ in group $\mathrm{A}$ and group $\mathrm{B}$, respectively). Manjunath et al. ${ }^{27}$ and Chakmakchi et al. ${ }^{28}$ advocated that due to the IPN structure of the Everstick an inter-diffusion bonding phenomenon occurs which enables the stick resin to penetrate the post, thus establishing a strong bond to dentin via the resin cement.

Based on the findings of this in vitro study and other researches, it can be said that meticulous selection of the restorative material that possesses optimal strength and fracture toughness for the rehabilitation of fractured teeth can lead to achieving desired treatment outcomes.

Since it is an in vitro study, it is an inherent limitation of this investigation. The fracture patterns were standardized and a static load was applied across all samples which is not the case in a clinical scenario.

Thus, results cannot be directly extrapolated to the clinical scenario. Hence, further research is required in this direction to corroborate the choice of the best materials and restorative techniques in the management of cases of coronal fractures.

\section{Conclusion}

Within the parameters assessed and inherent limitations of the present in vitro investigation, it can be said that the remaining tooth structure must be preserved as it offers significant resistance to fracture. As in the present study on the application of load from the palatal side, teeth having a labiopalatal fracture pattern offered significant resistance to fracture due to the remaining labial tooth structure. Also, Everstick post showed significantly high resistance to fracture when compared with the other FRC post (Ribbond) and thus can be a promising alternative to the conventional post-core 
systems and other FRC post systems. However, further in vitro and long-term in vivo trials are required in this direction to confirm and correlate the present findings.

\section{Clinical Significance}

The study represents a clinical scenario of a complicated crown fracture with available intact fractured fragments and gives an insight into techniques and restorative materials which can prove helpful in the management of such cases. The study opens an introductory gate in support of the clinical implications of the Everstick post.

\section{References}

1. Piskorowski JH. Traumatic intrusion of a tooth: a case report. Dent Today 2006;25(2):98-101.

2. Vijayaprabha K, Marwah N, Dutta S. A biological approach to crown fracture: fracture reattachment: a report of two cases. Contemp Clin Dent 2012;3(Suppl 2):S194. DOI: 10.4103/0976-237X.101091.

3. Pagliarini A, Rubini R, Rea M, et al. Crown fractures: effectiveness of current enamel-dentin adhesives in reattachment of fractured fragments. Quintessence Int 2000;31(2):133-136.

4. Tonini R. An innovative method for fragment reattachment after complicated crown fracture. J Esthet Restor Dent 2017;29(3):172-177. DOI: $10.1111 /$ jerd.12281.

5. Chosack AB, Eidelman E. Rehabilitation of a fractured incisor using the patient's natural crown. Case Rep J Dent Child 1964;31(1):19-21.

6. Taguchi CM, Bernardon JK, Zimmermann G, et al. Tooth fragment reattachment: a case report. Oper Dent 2015;40(3):227-234. DOI: 10.2341/14-034-T.

7. Macedo GV, Diaz PI, de O Fernandes CA, et al. Reattachment of anterior teeth fragments: a conservative approach. J Esthet Restor Dent 2008;20(1):5-18. DOI: 10.1111/j.1708-8240.2008.00142.x.

8. Ramesh P, Mathew S, Murthy SB, et al. Efficacy of Ribbond and a fibre post on the fracture resistance of reattached maxillary central incisors with two fracture patterns: a comparative in vitro study. Dent Traumatol 2016;32(2):110-115. DOI: 10.1111/edt.12223.

9. Sapna CM, Priya R, Sreedevi NB, et al. Reattachment of fractured tooth fragment with fiber post: a case series with 1-year followup. Case Rep Dent 2014;2014:376267. DOI: 10.1155/2014/376267.

10. Ozcopur B, Akman S, Eskitascioglu G, et al. The effect of different posts on fracture strength of roots with vertical fracture and re-attached fragments. J Oral Rehabil 2010;37(8):615-623. DOI: 10.1111/j.13652842.2010.02086.x.

11. Tuloglu N, Bayrak S, Tunc ES. Different clinical applications of bondable reinforcement Ribbond in pediatric dentistry. Eur J Dent 2009;3(4):329. DOI: 10.1055/s-0039-1697453.

12. Ribbond-Dental Fiber Reinforcement. [Company Brochure] [Internet]. Available at: http://www.ribbond.com/.
13. Deepa VL, Reddy SN, Garapati VC, et al. Fracture fragment reattachment using projectors and anatomic everStick post ${ }^{\mathrm{TM}}$ : an ultraconservative approach. J Int Soc Prev Community Dent 2017;7(Suppl 1):S52. DOI: 10.4103/jispcd.JISPCD_151_17.

14. AEIGS Dental network [Internet]. Available at: https://www. aegisdental network.com/.

15. Karre D, Muppa R, Duddu MK, et al. Fracture resistance of reattached fragments using three different techniques with emphasis on vertical grooves and fiber-reinforced composite post: a novel technique. JCD 2017;20(6):474.DOI: 10.4103/JCD.JCD_144_17.

16. Andreasen JO, Andreasen FM. Classification, etiology and epidemiology. In: Andreasen JO, Andreasen FM, ed. Textbook and color atlas of traumatic injuries to the teeth. 3rd ed., Munksgaard, Danmark: Copenhagen Publishers; 1994. pp. 151-177.

17. Stokes AN, Hood JA. Impact fracture characteristics of intact and crowned human central incisors. J Oral Rehabil 1993;20(1):89-95. DOI: 10.1111/j.1365-2842.1993.tb01518.x.

18. Murchison DF, Burke FJ, Worthington RB. Incisal edge reattachment: indications for use and clinical technique. Br Dent J 1999;186(12):614619. DOI: $10.1038 /$ sj.bdj.4800178.

19. Yilmaz Y, Zehir C, Eyuboglu O, et al. Evaluation of success in the reattachment of coronal fractures. Dent Traumatol 2008;24(2):151158. DOI: 10.1111/j.1600-9657.2007.00532.x.

20. Shirani F, Malekipour MR, Manesh VS, et al. Hydration and dehydration periods of crown fragments prior to reattachment. Oper Dent 2012;37(5):501-508. DOI: 10.2341/10-130-L.

21. Machado J, Almeida P, Fernandes S, et al. Currently used systems of dental posts for endodontic treatment. Procedia Struct Integ 2017;5:27-33. DOI: 10.1016/j.prostr.2017.07.056.

22. Torabi K, Fattahi F. Fracture resistance of endodontically treated teeth restored by different FRC posts: an in vitro study. Indian J Dent Res 2009;20(3):282. DOI: 10.4103/0970-9290.57359.

23. Misar $\mathrm{P}$, Hiremath $\mathrm{H}$, Jain $\mathrm{P}$, et al. A biologic approach to crown fracture: fragment reattachment with ribbond for immediate esthetics: a case report. Int J Appl Dent Sci 2016;2:93-95.

24. Newman MP, Yaman P, Dennison J, et al. Fracture resistance of endodontically treated teeth restored with composite posts. J Prosthet Dent 2003;89(4):360-367. DOI: 10.1067/mpr.2003.75.

25. Dean JA, Avery DR, Swartz ML. Attachment of anterior tooth fragments. Pediatr Dent 1986;8(3):139-143.

26. Mangoush E, Säilynoja E, Prinssi R, et al. Comparative evaluation between glass and polyethylene fiber reinforced composites: a review of the current literature. J Clin Exp Dent 2017;9(12):e1408e1417. DOI: 10.4317/jced.54205.

27. Manjunath P, Sujatha I, Jayalakshmi KB. Comparison of fracture resistance of endodontically treated teeth restored with two different fiber posts. Int J Appl Dent Sci 2017;3:197-201.

28. Chakmakchi M, Rasheed R, Suliman R. In vitro comparative assessment of fracture resistance of roots restored with everstick fiber reinforced composite post. J Oral Dent Res 2015;2(1):43-50. DOI: $10.12816 / 0017635$. 